\title{
Khobar City Plan and the New Public Space in Saudi Arabia
}

\author{
Atef Alshehri \\ atef.aa@gmail.com \\ Lulu Almana \\ ARUP, United Kingdom \\ lulu.almana@arup.com
}

\begin{abstract}
The launch of Khobar's city plan in 1947 as the first planned city in Saudi Arabia marked a radical shift in local public realm, which changed from pre-industrial organic and intimate public space to one that is car-oriented and formal in its geometry. This study examines the impact of this radical shift by focusing on one particular street, King Khalid street, which was once the bustling urban spine and the public face of the new city of Khobar. Data was collected from multiple sources given the inconsistency in the documentation of the planning and development process of the city. This included relevant popular as well as specialist literature, archival maps, historical photographs, and interviews with local residents who grew up or lived in the city for most of their lives. In addition, brief fieldwork was conducted to assess and examine the current street conditions. In comparison to the desolate current condition of King Khalid street, this study reveals multiple factors which helped to galvanize the exceptional position of this street in the past as a primary public space within a seemingly consistent grid. These factors include accessibility, scale, architectural characteristics, economic offerings, and the general urban experience. The study concludes by discussing ways to revitalize the street based on parallel experiments from the region.
\end{abstract}

Keywords: Khobar, Saudi Arabia, oil towns, public space, street life

To cite this article:

Alshehri, A., Almana, L.. (202I) Khobar City Plan and the New Public Space in Saudi Arabia, The Journal of Public Space, 6(I), 215-234, DOI 10.3289I/jps.v6il.I323

This article has been double blind peer reviewed and accepted for publication in The Journal of Public Space. 


\section{Introduction}

The story started in 1947 when the Arab American Oil Company (Aramco) planned Khobar to provide accessible urban amenities for its expatriate staff, and accommodate the influx of Saudi population coming from other parts of the country to live and work in the nascent oil industry town. Up until that point, there were no planned cities in Saudi Arabia, which had at that time a fragile economic base and a predominately rural population. It can be inferred that Khobar exemplifies "the industrial revolution" of Saudi Arabia.

There is no consistent documentation of the planning and development of King Khalid street or the city of Khobar in general. Thus, our methodology is not orthodox. For lack of archival sources on Khobar, we followed a detective approach where we focused on popular and alternative media, oral stories, news media, and ephemera such as postcards and anything that speaks about the urban experience of Khobar residents. In addition, Khobar first planning process is not well documented, so we resorted to mentions of this process in contemporaneous news reports. In addition, we documented the status quo of King Khalid street by walkabout on-site, experiencing the place first-hand and taking photographs. Overall, we tried to merge popular media with facts on the ground as we saw them.

Specialist literature indicates that Khobar was the first city planning attempt in Saudi Arabia. As such, it was born in a complete regulatory vacuum, with no local precedent or professional regime to inform the planning process ((Al-Hathloul and Anis-urRahmaan, 1985, p. 207). The formal grid was simply transplanted "as is" into the landscape of what became the city of Khobar. This astonishingly abrupt urbanization experiment had established a new norm of place making unprecedented in a country that was still deeply rooted in its heritage. Public space, which was once organic, intimate and human-focused became formal and automobile-oriented. The street, which is essentially an automobile path, emerged as the new form of public space. Khobar's character became the consistency of its grid, and it's urban life gradually centred along one particular street; King Khalid street (figures 4\&5).

King Khalid street represents the image of the first modernist experiment of new city planning in Saudi Arabia in the post-World War II period. It is characterized by its human scale, mixed land use and medium density. From a design and planning perspective, the street has the physical qualities that promote a lively streetscape and can strengthen the social fabric of the communities around it. On both sides of the oneway street, a new urban scene was staged with new building types, new architectural forms, materials and methods. The street became like a public display of how a modern Saudi city should look like. Other Saudi urban planning projects such as creating the AlMalaz district in Riyadh in the early 1950s followed the rubric of Khobar (Al-Hathloul and Anis-ur-Rahmaan, 1985, p. 208).

On a social level, King Khalid street is associated with many under-represented oral stories and particularities of the city that are known to local citizens. It was the place to interact with one another intentionally and coincidentally, where street vendors, oud musicians and young children playing football shared the street surface.

Despite its original central and accessible location, currently the street situation is deteriorated and suffers from abandonment. The retail shops are empty and plastered with 'to let' posters. The quality of buildings is degrading, and on a pleasant evening in December there is no street activity in sight. King Khalid Street is a form of modern 
Saudi public space that has been neglected by local municipalities and local retail and is very vulnerable today to being damaged, destroyed and lost (figures 8 \& I0).

\section{Origins of Saudi Arabia's first city plan}

Looking at the state of the urban settlements in Saudi Arabia at the early $20^{\text {th }}$ century, cities like Riyadh, Jeddah and Hofuf varied in size and location but were similar in their traditional urban form. Characterized by city walls that wrapped around dense clusters of houses and winding paths that centred around mosques and open-air markets, these cities shared a similar language but with distinctive identities. This identity was shaped over time by the climate, local culture and their basic economies.

Although oil exploration started as early as 1933 and crude production in 1938, oil production and export witnessed a sharp increase only after World War II. This led to drastic social, economic, and urban changes in the eastern province of Saudi Arabia where Aramco ran its operations. During that period, existing urban conditions were still deeply rooted in their old heritage. The economy was predominantly based on limited agriculture, fishing and pearling. Oil enterprise accelerated economic growth in a quantum leap by a few hundred years. The new mode of industrial development superimposed a twentieth century business on a fifteenth century economy (Farmer, 1959).

This sudden and abrupt disruption of local conditions is best explained by an eyewitness who lived through these changes. Mr Nassir Ajmi, who rose from an oil labourer in 1950 to an Aramco executive decades later, wrote: "I came from the desert. By the age of seven I knew everything that my father knew. I thought that was it, but then you see all the new equipment and machines. It's not a camel, it's not a donkey, it's not a horse, it's not a sheep, and it's not a goat. Then your mind begins to tell you that you don't know everything. You want to know more and that's how it started." The sheer scale of change rippled into every aspect of people's lives (Ajmi, 1995).

Like many of the traditional settlements along the shores of the Arabian Gulf, pre-oil era Khobar was a small fishing site that was occasionally occupied by fishermen. Before 1940, the oases of Hofuf and Qatif were the only major permanent settlements in the Eastern province with more than 10000 inhabitants within a vast desert which remained virtually unpopulated for many centuries (Barth and Quiel, 1986, p. 257). When oil exploration started in 1933, Khobar grew as an oil industry camp site and a marine unloading port for materials and equipment brought to Dhahran oilfield from the nearby island of Bahrain. Soon, Khobar became a small port with a single pier and a movement corridor developed between Khobar and Dhahran, $10 \mathrm{~km}$ to the northwest. This corridor was simply a graded road along which small retail and informal settlements developed (figure I).

Until oil was commercially produced in 1938, internal migration in Saudi Arabia was at its minimum. The pre-oil economic base of Saudi cities could not support high concentration of population. However, oil changed this situation forever, and the attraction of Khobar in particular drew a diverse population from nearby towns, other parts of Saudi Arabia and abroad. In 1934, the small Khobar fishing village had only 75 residents or so. This number multiplied many times in less than two decades to 13000 inhabitants by 1951. The growing city not only provided employment and business opportunities but also lifestyle offerings which could not be found anywhere else in Saudi Arabia at that time (Shuaiby, 1976). 


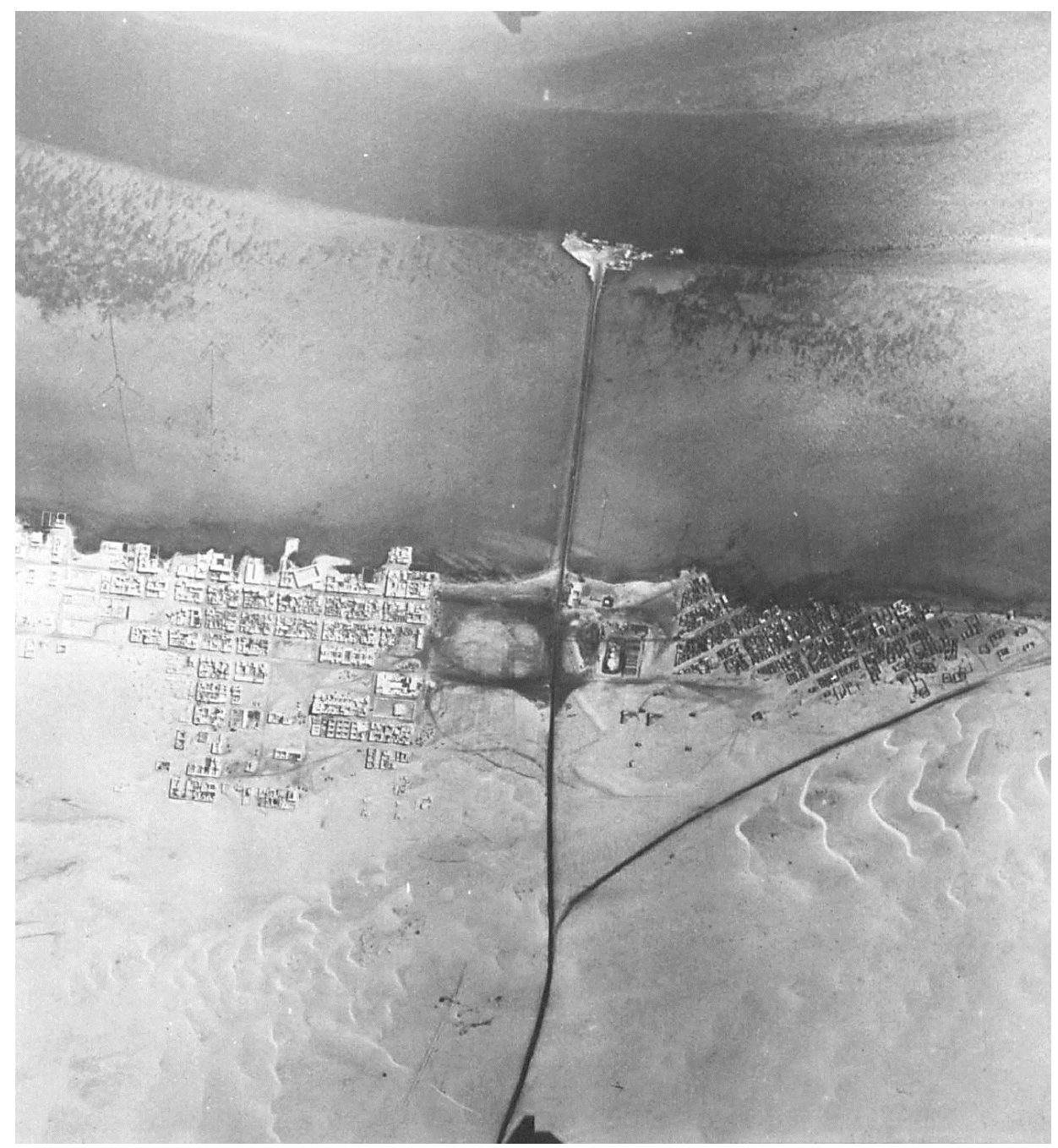

Figure I Khobar grid in 195I after three years of its launch. The pier extends into the Gulf (towards the top of the photograph). Dhahran road extends from the pier towards Dhahran camp (towards the bottom of the photograph) (Source: Shuaiby, 1976)

Urbanization of Khobar was not only triggered by the private oil enterprise, but also by public policy. In particular, the government land distribution act of 1939 was instrumental in opening the city for development. According to this act, any Saudi citizen was entitled for a land lease in Khobar awarded by the government free of charge for ten years, but to be developed within two years of receipt (Almulla, I991, p. 286). Not only Saudi citizens were attracted by this opportunity but also residents of other Gulf countries sought to be naturalised as Saudi citizens in order to acquire land in Khobar (Ham, 1944, p. 70). As a result, internal and external population influx accelerated. In particular, settlement intensified and squatter sites mushroomed around Khobar and oil operations sites in Dhahran. The squatter settlement in Dhahran continued to exist until the mid-1980s (Parssinen \& Talib, 1984, p. 14) (figure 2). 


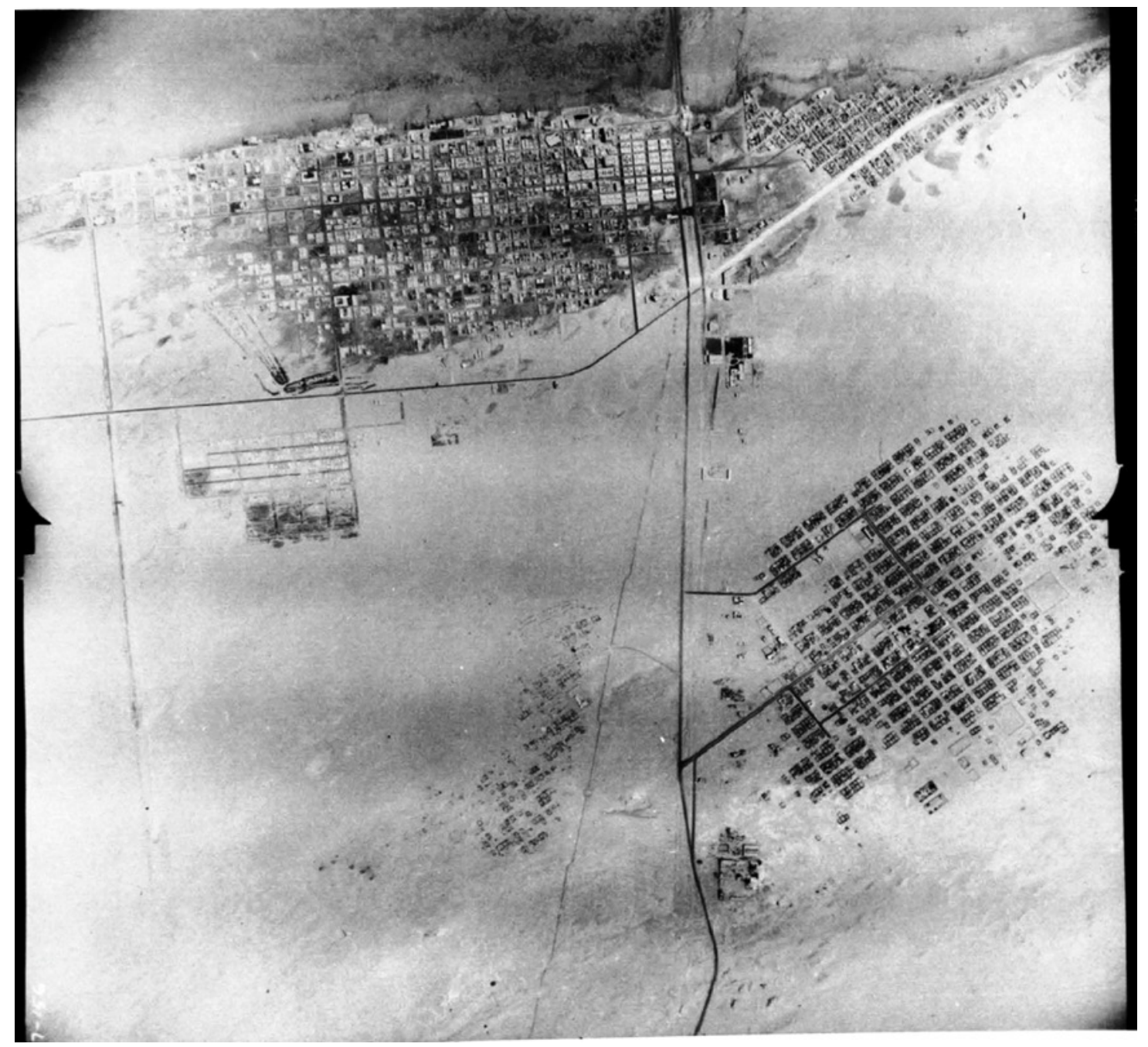

Figure 2. Aerial photograph of Khobar in 1962 showing Dhahran arterial road connecting the pier (top of the picture) to Dhahran, with squatter settlements on both of its sides. (Source: Shuaiby, 1976)

The pressure of rapid urbanization and population influx prompted local government of the eastern province to enlist the help of Aramco to produce the first overall plan of Khobar. Aramco's involvement as a development agent was stipulated in the 1933 concession agreement, which required the Aramco to "carry out public works development." Aramco, however, avoided engaging in activities with no direct connection to profit, which the company perceived extraneous to its core business (Vitalis, 2007).

Social pressure was also an important factor in accelerating the creation of a new city. In particular, the stark contrast between the all-American gated community of Dhahran and the shanty camps of Arab and other foreign workers reached a tipping point in 1945, when the first worker strikes took place over living conditions and pay (Chalcraft, 201 I, p. 38). Although Khobar planning was at the behest of the government, Aramco found it an opportunity to quench its labour workforce demands, and also to project an image of "the public good" agent to the community. 
All things considered, Khobar- being not too close and not too far from Dhahran campwas an ideal location to plan a nearby city that would absorb labour pressure for better living conditions. Not only that but also establishing a new city would relieve Aramco from future development obligations by providing a base for home-grown services in the new city. For this purpose especially, Aramco established "Arab Industrial Development Department," to support local entrepreneurs and businesses to create public amenities, such as Khobar electric power and water companies which were established in $195 \mathrm{I}$ and 1955 respectively, to name a few (Vitalis, 2007, p. 133). On a larger scale, Aramco established its own home ownership program which provided loans and technical support to its Saudi workforce in several cities including Khobar, in which an urban division called "labour town" was established to the west of King Khalid street (Al Mubarak 1999, p. 40).

\section{The company town typology and the street as the new public space}

One of the most striking features of Khobar plan is the adoption of a strict gridiron spatial configuration based on a network of streets and city blocks almost entirely identical in terms of scale, with some variations (figure 3). This newly conceived typology of urban space was unprecedented on such a scale in Saudi Arabia, whose cities maintained - up until that point - a predominantly traditional urban fabric. For the first time, public realm changed from traditional pedestrian-focused, condensed urban spaces, such as squares (Arabic: maydan), linked by alleyways to a landmark or a market, to linear and extended thoroughfares dominated by car movement.

There is no clear explanation, however, as to why the grid was adopted as the framework for Khobar, which Aramco surveyors devised in 1947 (Al-Hathloul and Anisur-Rahmaan, 1985, p. 206). An answer could be interpreted from prior urban experiments of oil industry in other places of the world. Before venturing to Saudi Arabia, the founding companies of Aramco, such as Standard Oil of California and Texaco had already established oil industry in Mexico and South America where they developed their policies and understanding of working in farther frontiers within different cultural contexts. In fact, the first generation of Aramco American pioneers came from the oil fields in South America where the exclusive company town typology vs. separate accommodation for local workforce was the norm (Abrams, 1966; Vitalis, 2007, p. 54).

The urban planning model that Aramco established in Dhahran and Khobar is not different from the company towns built by American oil companies in North and South America, which in themselves went through several cycles of development (Croly, 2014). The post-World-War II iteration of the American company town included two or three distinct forms of urbanism that are designed differently to serve different communities. The first form of urbanism is a district for senior staff, characterized by detached townhouses with large gardens, lush landscapes and wide undulating streets that resemble the Garden City movement in the UK and post-war American suburban neighbourhoods (Crawford, 1995). This is then juxtaposed with rectilinear grids and dense neighbourhoods for junior, local or low-skilled staff. 


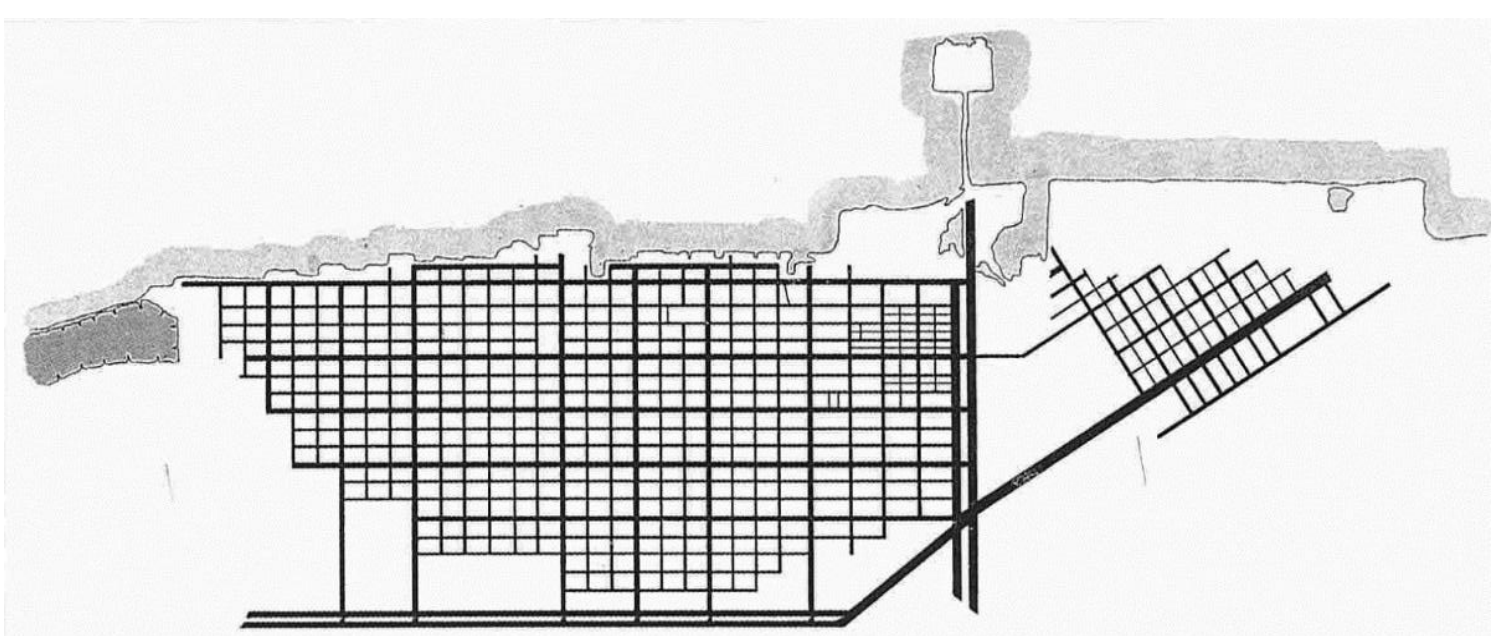

Figure 3. Khobar gridiron spatial configuration was a drastic departure from the existing traditional urban form in Saudi Arabia . (Source: Winterhalter, 1989, p. II48)

The roots of this spatial segregation go back to colonial urbanism practices linked to extraction industry, such as in remote mining sites (Fuccaro, 2013). Adoption of the grid could be interpreted as a means to maximize efficiency of construction methods and building materials consumption (Correa, 2016). Indeed, Khobar was a completely flat "tabula rasa" situation where a transplant of a tried and tested typology was a comfortable choice for Aramco, given the lack of any direct local precedent or standards.

On the other hand, for Saudi Arabia, the introduction of the grid was a radical departure from the common urban experience of the time, which was still rooted in the pre-industrial organic form. A city-wide network of perpendicular streets emerged as a substitute to the condensed and human-oriented traditional public space. The shifts were not only configurational, but also functional. The new city grid was devised based on the assumption that car will be the primary means of transport. Consequently, land use and urban functions were spread out across the plan in designated areas, in line with the modernist planning ideals of the post-war period. This deterministic approach and the focus on separation of uses characterized the new and emerging Khobar (Lesnikowski, 1982).

Despite some of the pitfalls of Khobar Cartesian street grid, its effect presented a new way of creating urban realm through "standards." Aramco planners of Khobar worked in complete regularity vacuum. There were no local street or design standards to use, nor was there a professional practice environment to be a "guiding hand" for the planning effort. Thus, the impact of Khobar planning was compounded not only because it was unprecedented, but also it would later be taken as a basis for planning other Saudi cities.

The introduction of these standards for the first time might seem benign, but in fact their effect is enormous on place-making in future Saudi Arabia. Simple dimensions for minimum street width, sidewalks, or planting strips may seem now unremarkable. However, in the case of Khobar, these urban features were not practiced at the time. Not only that, but their scale was overwhelming as they were applied to miles of streets and many city blocks occupied by thousands of people. These standards delineated the 
urban and architectural character of Khobar, and had a decisive impact on the way it looked, felt, and worked for its inhabitants and visitors (Southworth and Ben-Joseph, 2003).

The layout of Khobar blocks was not the only outcome of following the newly introduced standards, but the voids of the streets were also sculpted by the prescribed terms and conditions of these standards. Street facades, scale, environmental response and overall architectural character were all the outcome of the application of these repetitive standards. The grid meant that Khobar streets are generally straight and meet each other at right-angles. The original plan of Khobar had about 293 street intersections. The vast majority of streets (over $90 \%$ ) are $10-15$ meter wide. A small minority of streets falls below 10 meters in width. There are a few arterial streets, which can be as wide as 18 to 20 meters. They connect with major inter-urban roads to Dammam and Dhahran (Shuaiby, 1976, p. 211 ).

\section{King Khalid street as the new urban core}

Although Khobar's grid might seem geometrically orthodox on an abstract level, in reality it took a lot of qualities from the organic urban settlements which previously existed in the region. The formal rectilinear framework had multiple dynamic variables which changed over time and established micro-urban areas within the larger grid. Variables pertinent to the environment, real estate, governance, traffic and population movement patterns, to name a few, added extra layers which differentiated the seemingly consistent grid.

As an example of this differentiation process, King Khalid street is recognized as a key public space in the modern landscape of Khobar. It held high urban and cultural significance in the local social memory to the degree that it was often labelled "the Champs-Elysees of Saudi Arabia” (Al-Madani, I99I). It was the city's public promenade of choice where it hosted parades for several Saudi monarchs since the early 1950s. Having been lined with local and international shop fronts, the street established itself for half a century as a major destination for commerce and retail in the city and the wider region, and as a dynamic public space with a vibrant social life (figures 4 and 5). Local narratives are rich in delineating an intimate narrative of the rise of public life on King Khalid street. For instance, Younis Al-Hawwa, a jewellery business owner who worked on the street for the past fifty years, stated in a TV interview that although the city of Khobar was small with limited population size, merchants moved from Bahrain to Khobar in the 1960s to establish their shops in this street (Al-Hawwa, 2019). These merchants included families such as Al-Hashimi, Al-Kohaji, Khaja, Kanoo, Alfhaimi and others. They opened supermarkets, pharmacies, bookstores and jewellery stores on King Khalid Street.

Indeed, such anecdotes from the community's collective memory suggests that King Khalid street is one of the important historic places in Khobar, if not the most important one. This was captured in ephemera, such as postcards produced locally in the 60's and 70's, and currently in press and social media. This is most visible in Journal articles by local historians, such as Abdullah Al-Madani who wrote a weekly column on the history of King Khalid street in Alyaum newspaper (Al-Madani, 20I7). 


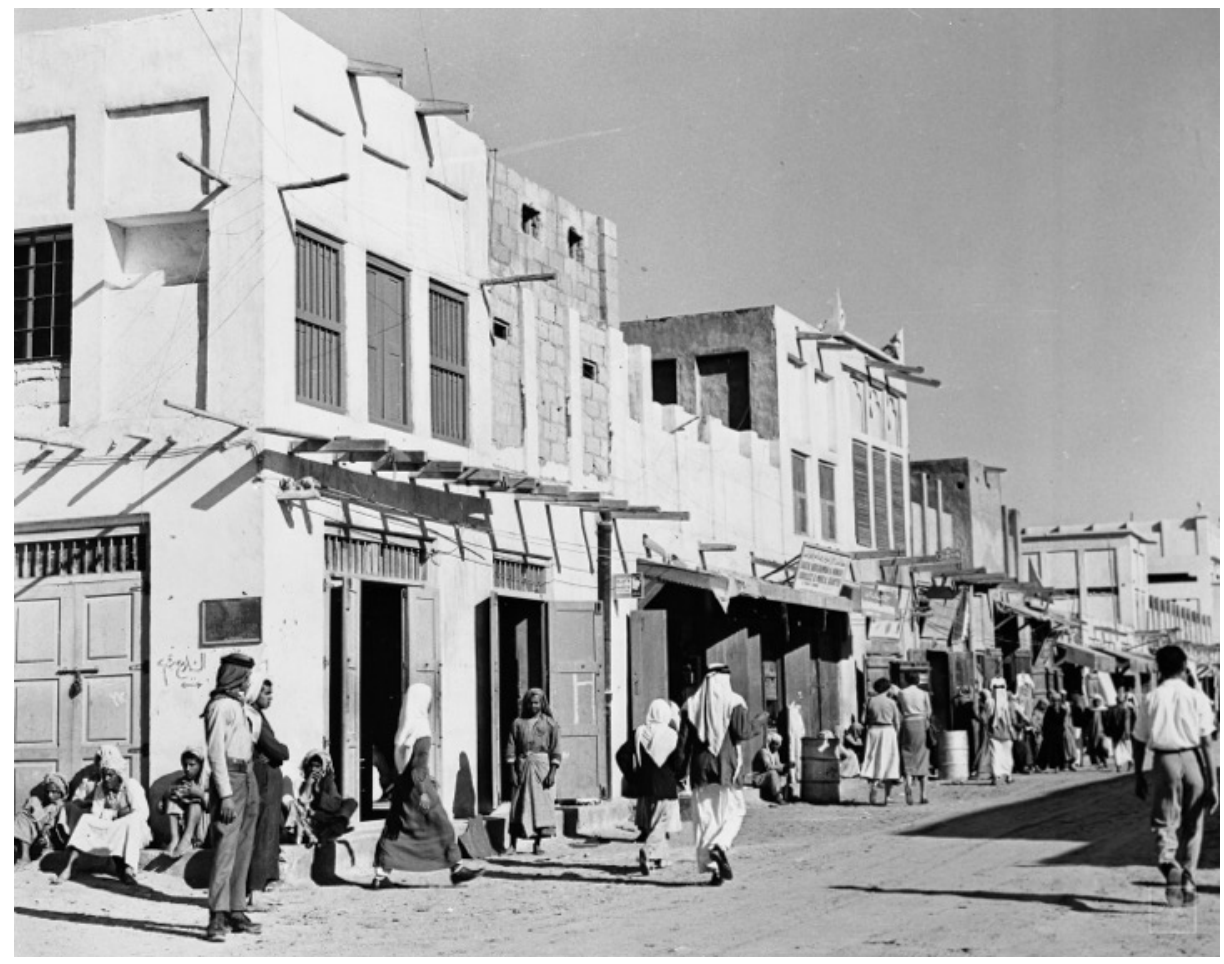

Figure 4. King Khalid street in 1954 showing architectural language still rooted in its traditional past (Source: Aramco)

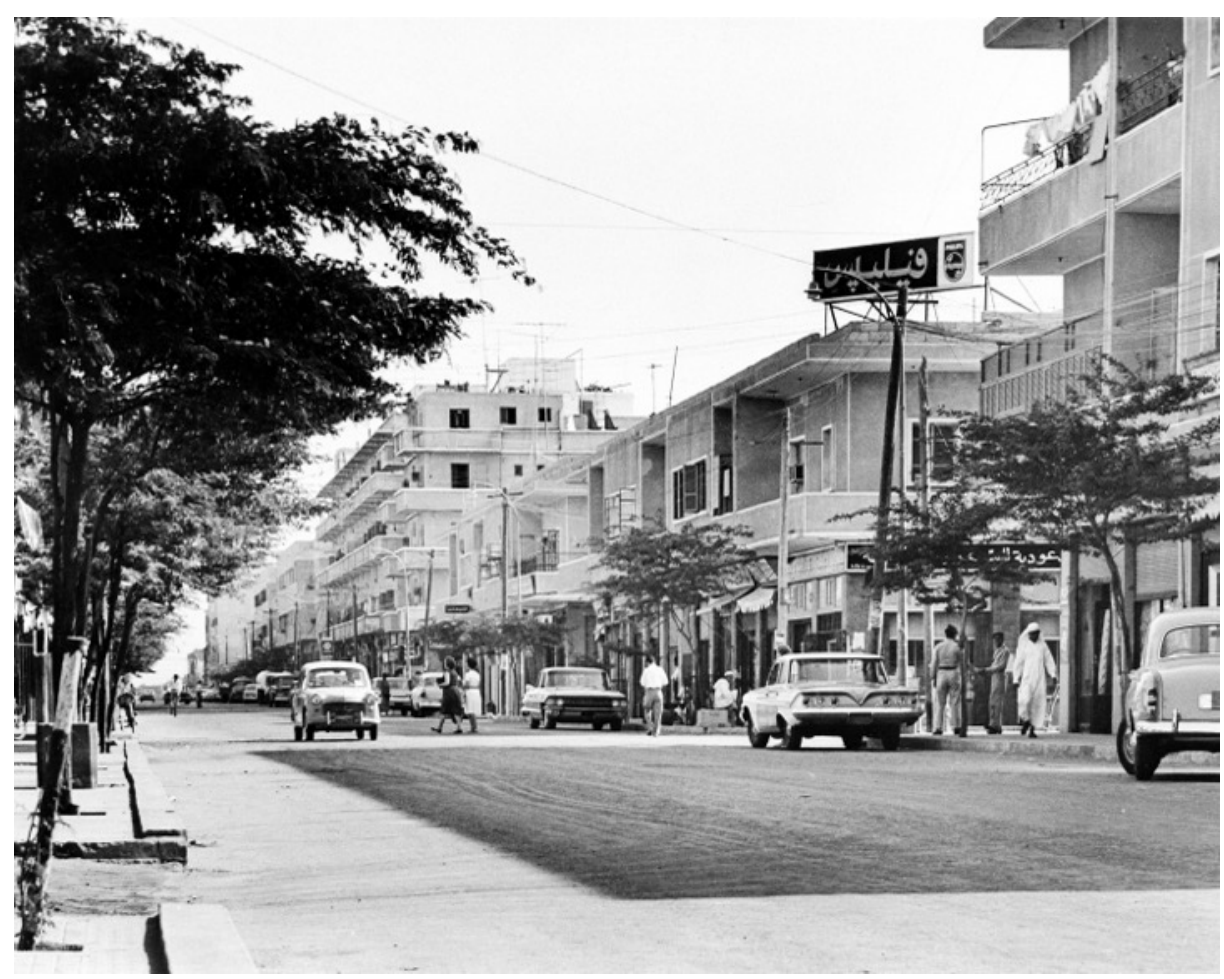

Figure 5. King Khalid Street in the 1960s with new architectural forms and building materials. (Source: Aramco) 
In another work, the same author expands on the past life of King Khalid street as "the city's beating heart and the centre of its financial and commercial activity and the meeting point for those coming from other cities to shop." Along the street, there are hundreds of shops, banks, offices, and restaurants where you can buy things as big as a car, or as small as shawarma (a local type of sandwich)" (Al-Madani, I99I).

Similar urban nostalgia is also apparent in other Gulf oil towns such as Al-Ahmadi in Kuwait which was established in 1947 (Alissa, 2013, p. 43). Al-Ahmadi differs from Khobar in that it was built, in the middle of the desert, as a satellite to Kuwait City. AlAhmadi was also planned as a composite town that included three tiers of urban design in one town; for senior staff, skilled workers and local workers. However, it holds the same popularity that King Khalid street does among its former residents. Nostalgia in the community's collective memory is not only a reflection of how people felt about the conditions of the past, but also a reflection of how people feel about the current situation. Among the conversations with former residents and retailers in Khobar, the praise of the street's vitality and active public life is consistently contrasted with the degraded conditions of the present.

Listening to these animated stories about an exceptionally successful public space from one side and observing its current state from another side prompts posing several questions. For instance, when and how the street started to develop as the urban core of Khobar. Also, what does it represent in the wider context of the city? Were any design features linked to the performance of the street? And why did this street in particular represent an image of the city's modern heritage?

In order to understand the value of King Khalid street, these questions should be considered from a spatio-temporal perspective. In the past, the street enjoyed excellent accessibility as it sat at the centre of Khobar (Northern Khobar today). The distance from King Khalid street to the coast was half of what it is today. It was the fourth street inland running parallel to the coastline before the spread of sea reclamation projects since the 1960's. This close proximity to the sea and the now-defunct port, which was within a ten-minute walking catchment gave the street an accessible and desirable location. The pier was the main point of access for goods and passengers from Bahrain and other countries.

This ease of access was coupled with the continuous and staggering demand on urban services and experiences. For example, for oil company staff coming into Dhahran from Bahrain, King Khalid street was a middle ground and an ideal urban hub for hotels, food outlets and other offerings. Proximity to regional destinations, such as Bahrain, Dammam, Qatif and Ahsa added to the ecosystem of trade, as it wasn't far from other economic and agricultural hubs. Aramco and its foreign employees and their families and visitors added to the diverse demand on retail and hospitality and allowed the local economy to flourish.

As part of a larger grid, King Khalid street shared a lot of configurational similarities with other streets nearby, but there are subtle morphological differences that played a role in allowing it to become an iconic public space. King Khalid street is approximately twenty meters wide. This is wider than most streets in Khobar, which ranged between ten and fifteen meters in width. Also the small scale of the short city blocks, which define both sides of the street, allow more permeability and comfortable pedestrian movement. This is right on the mark of how Jane Jacobs once described successful urban fabric: "frequent streets and short blocks are valuable because of the fabric of 
intricate cross-use that they permit among the users of a city neighbourhood" (Jacobs, 1993).

Moreover, the spatial proportioning of the street can be described as ideal. Street section dimensions are not too wide in relation to building heights, so pedestrians, trees, and retail frontages are sharing the same space, while enjoying passive shade from adjoining buildings that define the street façades. The soft landscape formed another street hallmark, as it was lined with local street trees at regular intervals, unlike other streets in the area, giving it a distinct character and more shade during the day. The extra width of five meters that differentiated it was enough to allow for street trees along both sides of the footpath, while still maintaining a comfortable pedestrian path with spill-out from restaurants and cafes. The effect of trees on image and public perception and beauty is important to consider. Overall, the planted trees provided a diverse range of social, economic and environmental values to the street.

The burgeoning of new architectural language in the street was one of the first signs of the economic growth in the early days of Khobar (figures 4\&5). During the 1930s and 1940s, the tectonic culture was still connected to its traditional past. This could be seen in some buildings which survived well into the 1950s, such as the first state school, which started in a rented house that displayed construction methods and materials, distinctive of the Eastern province architectural heritage. By the early 1950s, serious changes started to take place in infrastructure and technology. Mechanization of the building industry grew especially after Khobar Electric Power company started operation circa 1953, and provided power to the nascent construction industry (AlDossary, 200I).

In addition to newly introduced building materials, the homogenizing power of the standardized grid not only shaped streets and city blocks but also played a major role in the development of the new architecture in Khobar. The availability of new materials and new construction methods and techniques influenced architectural form. Not to forget that foreign expertise played a major role in transferring architectural practice to Khobar which was a fertile ground for it.

These spatial and architectural traits were essential to create an urban spine and a public space that functioned as a platform upon which the collective memory was inscribed. King Khalid street is considered a part of people's own heritage. It is linked to the thriving days of Khobar and its evolution. These are a few reasons that demonstrate the significance of this street from a public space perspective. Having design features that are human-centred and resemble globally successful and well-loved streets around the world show that it is also of value from an urban design perspective and could have been a model for new Saudi streets.

\section{Current situation: rise and fall}

There are clear economic factors that are part of King Khalid street's decline which this paper will only identify but without examining in depth. For example, competition from large-scale shopping malls, shifts in consumer experience preferences and new labour policies which drove some expatriate workforce out of the market. There is also a limited supply and variety of residential units in the area which lead to urban sprawl. In addition, the shift in traffic and highway systems affected the original configuration of King Khalid Street within the wider city mobility network and shifted its previously central position to a marginal one. 
Due to significant gaps in historical data, a qualitative study of a section of the street is presented here. The aim is to understand its historical character and growth process vs. how it currently performs. The study area is focused on the first segment of King Khalid street, stretching from The Custodian of the Two Holy Mosques Road (Formerly, Dhahran road) to Fourth street. In particular, two key points will be examined. First to be looked at is the intersection with the arterial Dhahran road, which was the main entrance to King Khalid street. Second to be examined is the block from "A Street" to First Street, which includes Kaki and Aldugaither buildings, where most of the retail activity occurred in the past. (Figure 6).

At the prime of King Khalid street's public life, during the 1960s and 1970s, the city of Khobar consisted of the newly formed grid which is where its entire population lived. However, the fact that that area is referred to now as Northern Khobar alludes to the fact that the city has expanded to the south, and in fact in all directions. The local population no longer lives in the area around King Khalid street as was the case before. This is an important factor relevant to the deteriorated conditions of the street today. Although Khobar and King Khalid street were designed for the car and around a formal network of streets, it wasn't designed entirely for that means of transportation. It relied heavily on a thriving local population that lived on the street or within walking distance. The disappearance of this residential population is one of the primary challenges that lead to the street losing its footfall and consequently losing its vitality as a public space. The point where King Khalid street intersects with Dhahran road was an important spatial node in the city as it connects Dhahran road as the primary functioning route (industry, oil, economy) to King Khalid street as the secondary route (leisure, retail). This was celebrated in the earlier plans with a green roundabout (figure 7). Dhahran road itself provided the regional connectivity as the first arterial road built in Khobar. As a straight route connecting Khobar pier to Dhahran oil fields, it embodies the narrative of the city and the reason it exists in the way that it does today. The greenery in the roundabout offers a visual link with the street trees along Khalid street as they seem to be from the same tree species, announcing to passers-by and vehicles that King Khalid street is a destination and a place to go to. This urban scene from the past is confirmed by contemporaneous residents of Khobar (Farran, 2019).

Over the last fifty years, this intersection has been redesigned and reconfigured to accommodate the changes and expansion of Dhahran Road. Comparing archival visual material with the current situation, it can be seen that the roundabout was demolished and substituted with a linear green park within the right-of-way, centred in the middle of Dhahran Road (figure 6\&7). This remained till the 1980's which gave consistency to the boulevard character of the road and provided significant urban greenery to the city of Khobar. However, as Dhahran Road widened, the lanes expanded, and the speed limits increased. The linear green park became isolated in the middle of six lanes, with three lanes on each side and very few street crossings.

Eventually more road works occurred on Dhahran Road leading to increased scale (and speed) as a major highway with twelve lanes, a tunnel, and no greenery nor space for pedestrians or cyclists. This shift in scale changed the relationship it had with the contrasting, and much narrower, King Khalid street. Today the intersection includes a higher proportion of road surface to footpaths than it did in the past, and there is no greenery or any shade. It is safe to say by looking at the current condition that the ratio of green to hard surfaces has decreased significantly. 


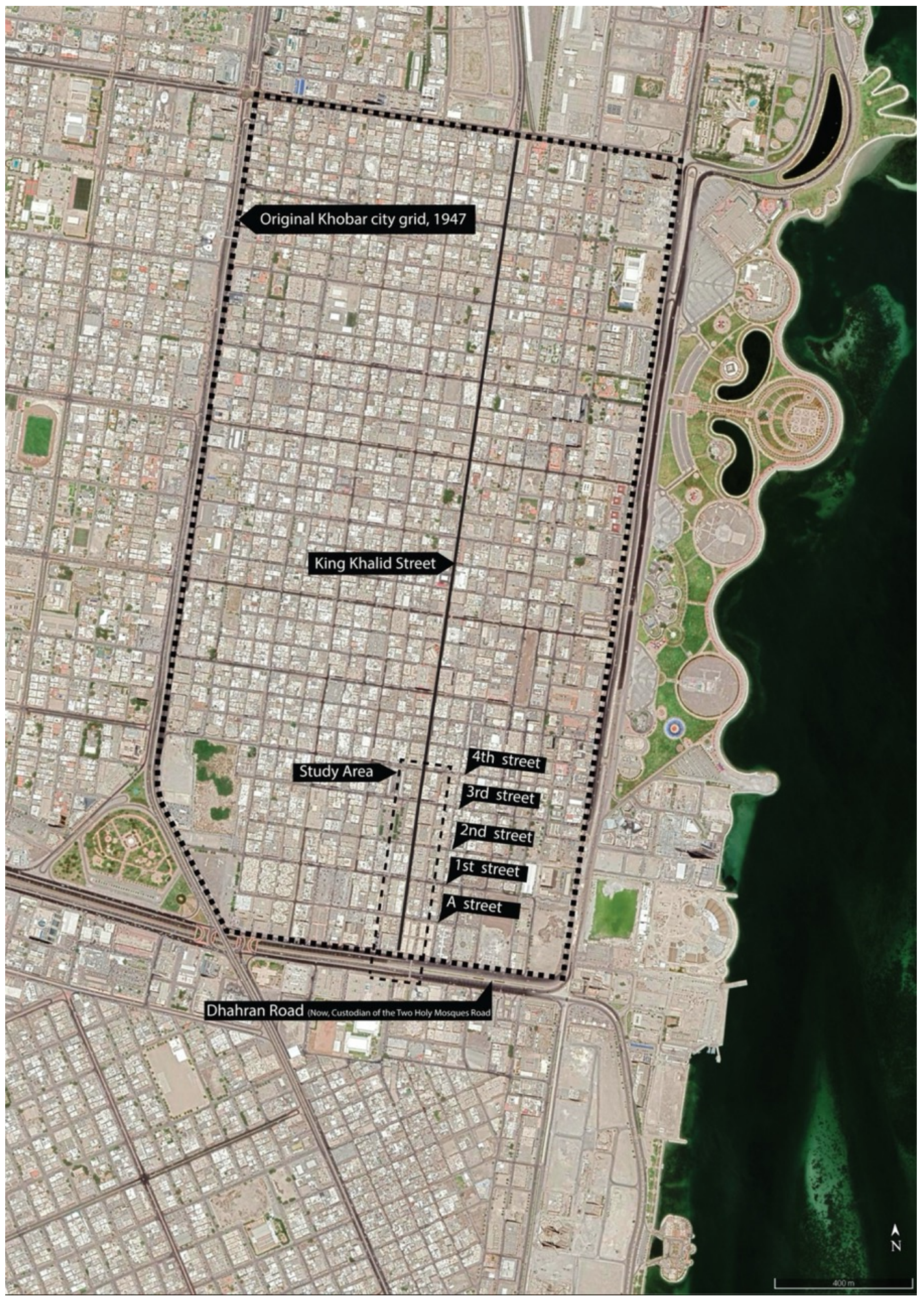

Figure 6. Study area along King Khalid street, within the original Khobar city grid of 1947 including intersections from 'Street A' to '4th street' (source: Author based on Google Earth image) 


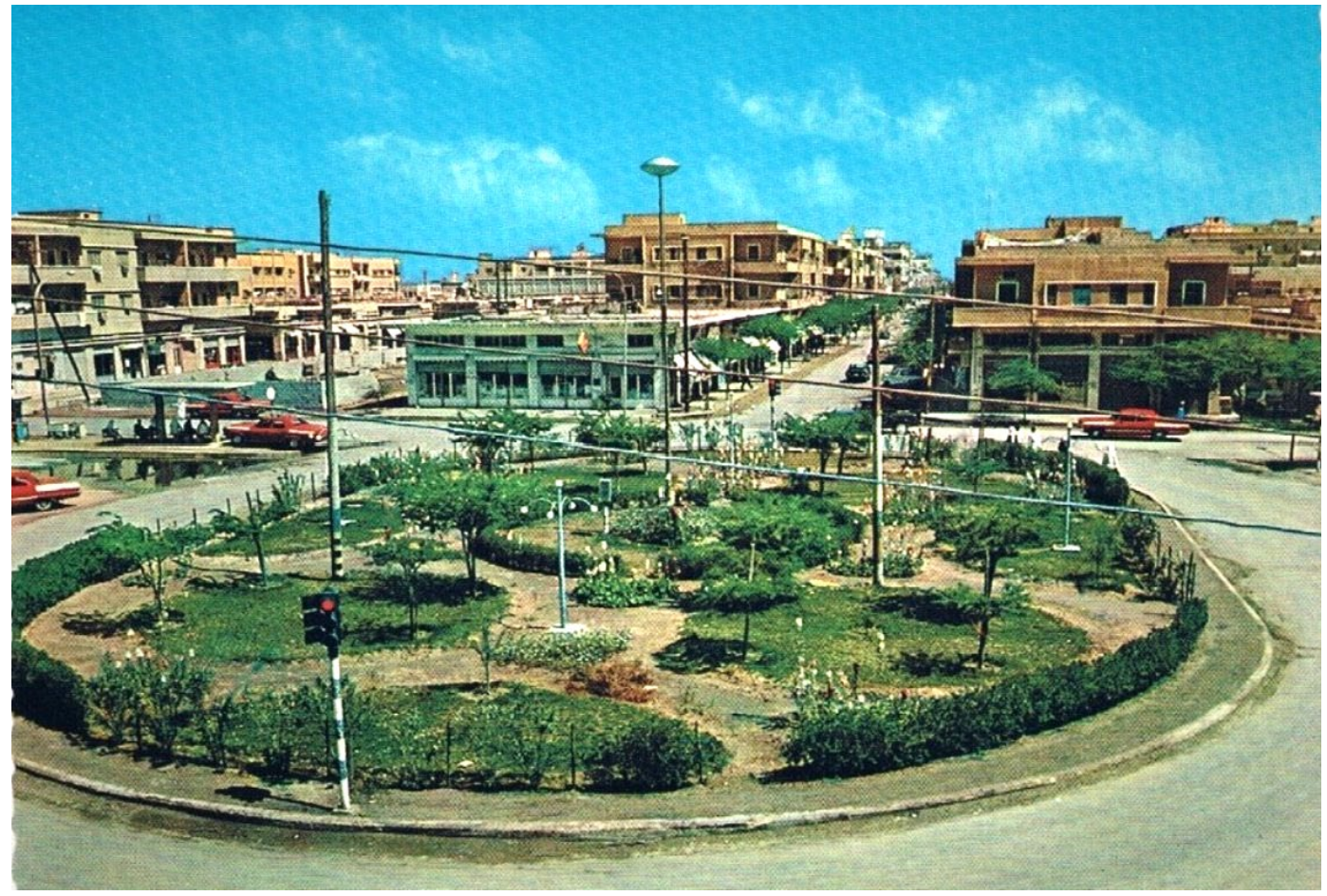

Figure 7. Postcard of a green roundabout at the intersection of the tree-lined King Khalid street (background) with Dhahran arterial road (foreground) circa 1968 (Source: Salah, n.d.)

There has been an attempt by Khobar Municipality to refurbish the area using new paving in 2010 (Farran, 2019). However, that was only a cosmetic treatment which could not alone create positive change (figure 8). It may have also differentiated between some of the buildings (deteriorating) and the public realm (renewed) which results in a fragmented street. Today almost ten years after the refurbishment initiative the street is suffering from economic regression, with a high percentage of vacant retail spaces and shop fronts with signs for rent. On a tactical level, this intersection was paved with interlock concrete tiles in varying colours, on both street and footpath surfaces. This effort is a cost-effective way to mimic cobbled streets. It resembles the global trend of 'shared streets' where the surface is shared amongst all users, including pedestrians, cyclists, and vehicles. This trend aims to equalize the hierarchy of the street by not giving priority to vehicle-drivers as it is currently the case in the neighbourhood and the region.

However, on a micro design level, the difference in the intervention here is that kerbs are still higher than the thoroughfare, there is a high number of bollards along the footpath which indicates that vehicles are dangerous and need to be protected from. This indirectly signals to motorists that speeding is accepted and perhaps even encouraged. These attempts remain tactical and on the surface. They don't resolve the profound strategic changes which affected how the street functions within the wider urban ecosystem.

The second point of examination is the first block between $A$ and First streets. In terms of urban landmarks, that segment is home to Kaki Buildings on both sides of the street. 


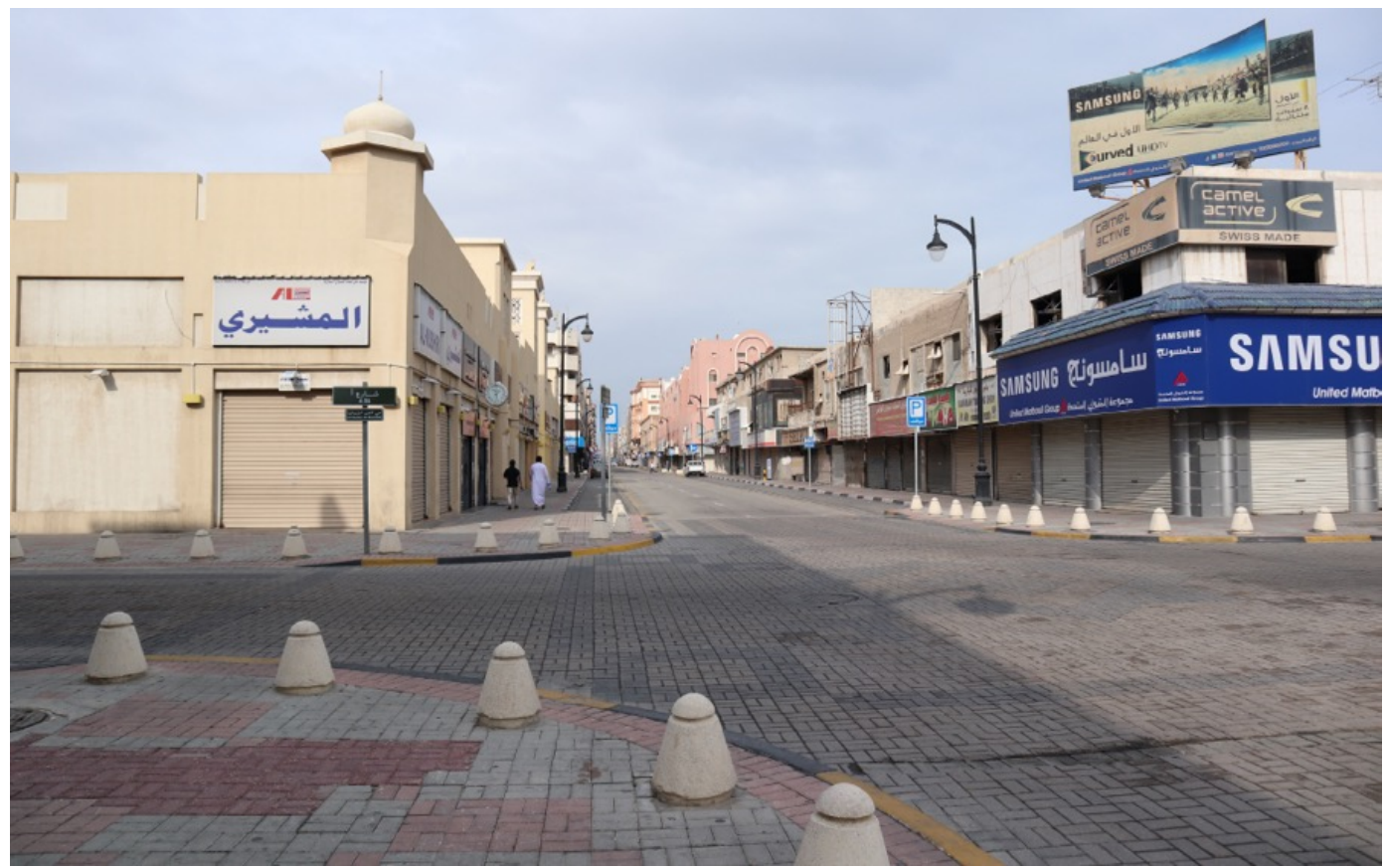

Figure 8. Refurbishment of King Khalid street. Photo taken in 2019 (Source: Author)

The Makkah-based merchant brothers Siraj and Sadaka Kaki acquired the land in an auction in the 1950s, and then started the first factory of cement blocks in the city of Khobar in 1954 to construct their new buildings. The buildings were initially developed as mixed-use multi-storey buildings with predominantly retail spaces, but then expanded to include an extra residential floor. The block also includes Aldughaither Building, another mixed-use plot developed by businessman Saud Aldugaither following the lead of Kaki family (Al-Madani, 1991).

The timeline photographs (figure 9) show the street evolution with a series of images taken from approximately the same vintage point. Starting from 1963, when the street was still in its infant years, we see the Kaki buildings as the main elements in the photograph. The thoroughfare is wide and laid with asphalt with no street markings. There are young trees lining the footpath that are roughly 3-4 meters high. Tall streetlights are placed every 10 metres and go up to six metres high. Signage is small and proportionate to shop fronts.

Comparatively, in the following photograph of 1968, the same view has matured and appears to be busier with a higher number of vehicles. There is a new light signal system hanging in the middle of the street which was not visible in the photo from five years ago. The trees have grown slightly in size and the middle building on the left side has been transformed into a hotel. Street life is more vibrant with a few visible vendors on the pavement. There are small interventions for thermal comfort, such as shop awnings and canopies signalling to more pedestrian activity. International trademarks and brands appear here such as the Coca Cola sign.

Third photograph shows the same view in 1974. The trees are significantly larger and have thick canopies that would provide substantial shade. The shops seem to all have awnings and shade canopies. There is heavy pedestrian activity and a group of people walking in the middle of the street indicating that vehicle speeding would have not been high. 


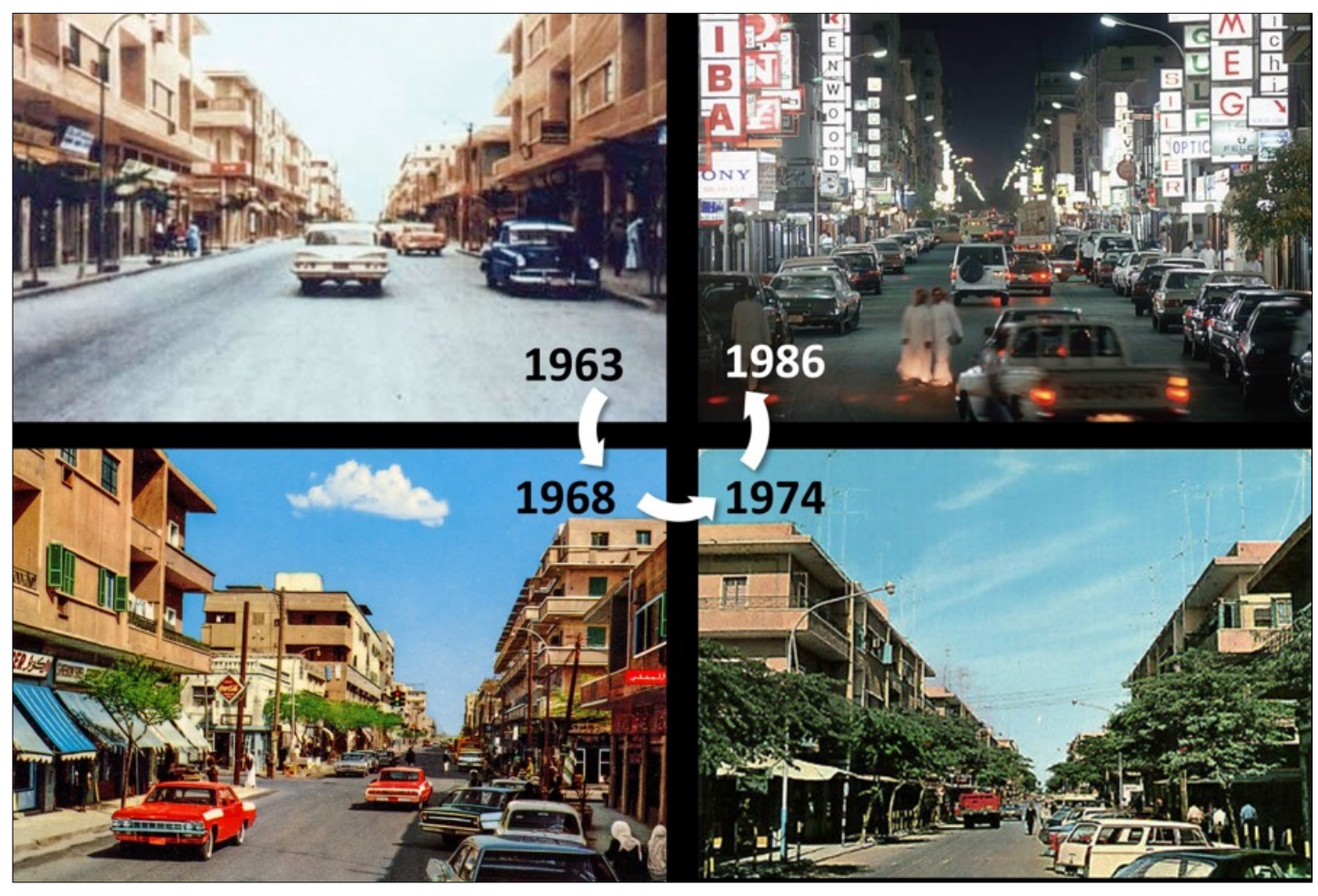

Figure 9. Timeline images of development on the first block of King Khalid Street from 1963, 1968, 1974 and 1986, respectively.

(Source: @Khobar_History, 2018; Al-Madani, 199I; Salah, 1963,1968)

The last photograph of the timeline shows the view in 1986 and a very different image of the street. The buildings are roughly the same in structure but have a much higher coverage of retail brands, advertisements and signs. Here we see the beginnings of a departure from the previous character in that the trees have been removed as well as a large number of shop awnings. The street has been furnished with a new scheme of street lighting including two types of white pedestrian light fixtures, one with round lights and the other with European-style lights. Shop signs have also been replaced by predominantly backlit signs.

Today the same block is quiet and empty. Many shops have no tenants. Architecture is derelict and, in some cases, falling apart (figure 10). Street lights have once again been changed and their height and orientation is focused on the road only and not the footpaths. There are no longer any shop awnings or street trees or any form of vegetation. Alleyways between the buildings are devoid of any human-scale features other than a selection of fixed concrete benches that are fixed to the ground.

Traditional shop fronts form a significant part of the architectural heritage in Khobar.

\section{Revitalization strategies}

The growth of King Khalid street reveals the impact of multitude of socio-economic changes fuelled by the "magic touch" of oil (Fuccaro, 20I3, p. 4). At present, this rise to prominence came to a halt, although King Khalid street has high potential for urban renewal and revitalisation. 


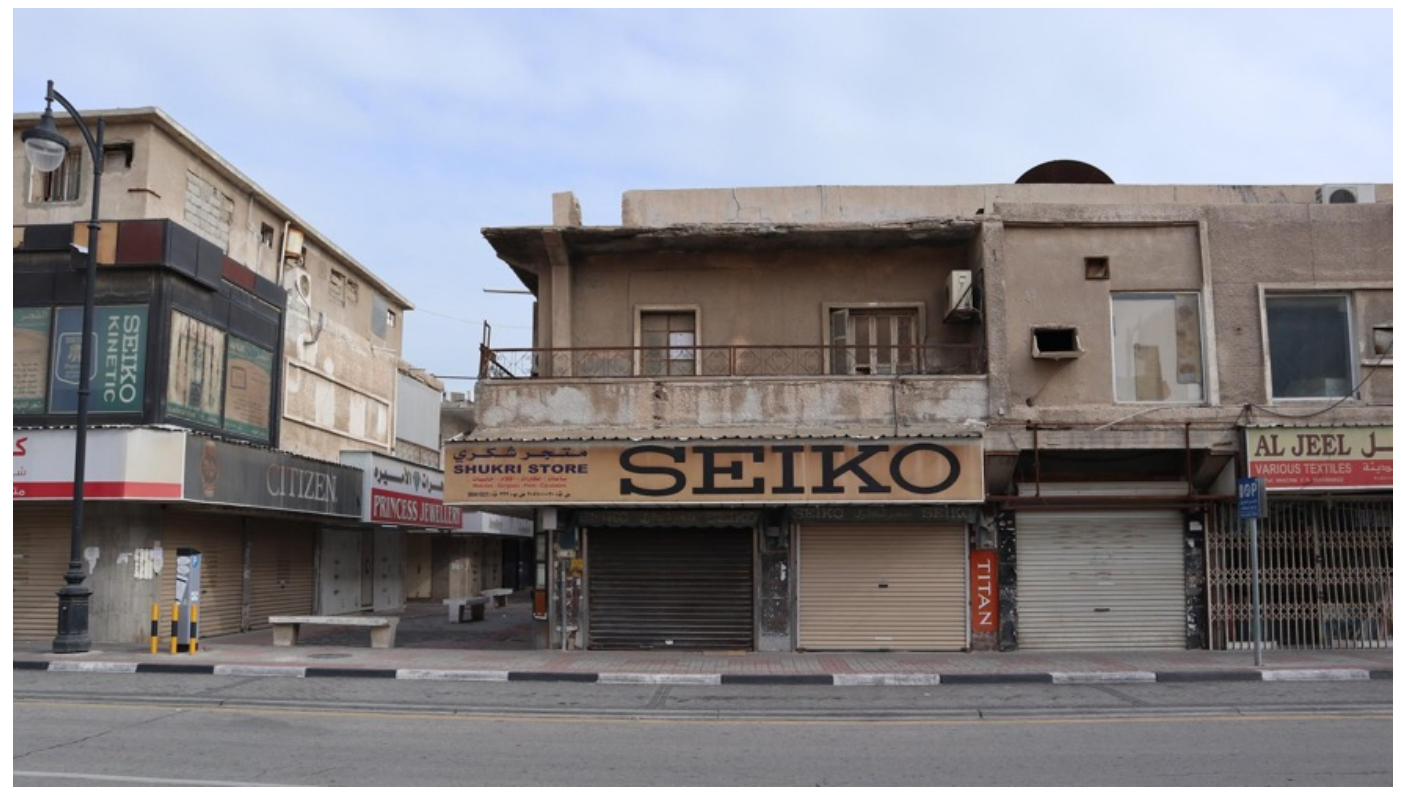

Figure 10. Kaki buildings today are in a deteriorated condition, similar to the condition of many of the past urban icons of King Khalid street, (Source: Author)

This section will discuss revitalization in the local context within Khobar, the differences between revitalization and gentrification, and then will look at the pros and cons of some methods and examples where this has been done in the past.

Today the term "urban revitalization" is used to describe a process that includes social and economic improvements in urban conservation planning. The main idea is that it is an integrative planning process that includes policy, urban design, heritage preservation and social and economic planning. It aims to address urban issues such as economic decline, architectural and environmental decay, community dereliction and social issues. It is usually an incremental process and happens largely through public effort, or publicprivate partnerships. For a small town like Khobar, this can bring several benefits such as efficient utilisation of existing urban infrastructure, reducing sprawl, providing more jobs in the city centre, attracting tourism, and providing a rich historic narrative that is diverse, authentic and unique to the city. Regeneration projects that set clear delivery or efficiency targets can also offer more positive outcomes (Mazzetto, 2018, p. 3). It also must be clear that urban revitalization is not only a process of upgrading the physical surface of a place, but also ensuring social and economic viability. There are many ad-hoc examples in Saudi Arabia and in Khobar that include efforts of upgrading the physical area to give the impression of positive change, such as the use of graffiti art in the oldest part of Khobar, Subekhah, in 2018 (Al-Fawaz, 20I8). While this may work in some examples of tactical urbanism, it is rarely enough to solve strategic urban problems such as a hollow city centre. It also creates an attraction for visitors to the area without necessarily improving the conditions for the local residents themselves. To ensure holistic urban revitalization for King Khalid street it must become both a home for a real diverse population living in the area and a destination for another population visiting for retail and cultural purposes, but not one without the other.

The second example of revitalization in the region is the Muharraq Pearling Path in Bahrain which is similar to King Khalid street in the sense that it represents a heritage narrative for the city and an economic industry which has been manifested in the urban 
fabric. For Bahrain, Muharraq is home to the pearling industry that declined in 1930's after the discovery of cultured pearls, whereas Khobar is the home of the oil industry and its beginnings in 1940s and 1950s. The revitalization of Muharraq is still ongoing. It is taking a positive phased approach that involves different stages and grows slowly over time with the communities within it. The preservation and rehabilitation of the buildings serves as a good precedent in the region.

Another benefit from this case study is that it is facilitated by a model of public and private partnerships that also engages with the relevant local families and landowners in the area. Some of the problems with this project so far is mostly related to design quality as the way-finding and signage is not clear, some of the urban plazas have low quality features including unhealthy trees. Lastly it is not clear if the local community was involved and engaged in the design and planning process. The project recently won the Agha Khan prize for Architecture in the 2017-2019 cycle (Aga Khan Development Network, no date).

On the other hand, a vision for revitalization can be seen in the third example of AlAhmadi town in Kuwait. Ahmadi is a centralised town that was established, owned and for a while run by the Kuwaiti Oil Company (KOC). A higher sense of centralised planning and development still exists to this date. For example, any modifications to the built form from the 1940s-1970s were not allowed without the company's permission. After 1975, the management of the company changed and has been turning a blind eye to the illegal expansions happening and illegal subletting which has had a negative impact on the architectural and urban form of the town as a whole (Alissa, 20I3, p. 56).

These expansions and changes are understandable as they reflect a desire from the new Kuwaiti residents to architecturally 'upgrade' their homes and facilities to meet Kuwaiti needs rather than British or foreign expatriates needs, such as introducing 'diwaniyat' (reception rooms for men social gatherings) outside the front of their houses.

Currently, KOC is developing a master plan titled the Ahmadi Township

Redevelopment, in which it aims to set a comprehensive plan for redevelopment through preserving Ahmadi's architectural and urban heritage while also providing the living conditions that the contemporary Kuwaiti population needs, and therefore fixing the problems faced by local residents in recent years (Alissa, 20I3, p. 58).

The challenge in revitalization is more than restoring and rebuilding the physical fabric of cities. It is to provide a thriving and diverse local economy in the centre of Khobar that is viable and can serve a diverse socio-economic community. It is important in the case of King Khalid street not to cause displacement within the local Saudi population. As there is a lack of data at this stage of the research about the number of residential population and their socio-economic backgrounds, it is only possible to describe the principles and goals without quantifying residents and their rent value. Further surveys will be needed to gain more information if the lack of quantitative data persists.

\section{Conclusion}

Creation of Khobar was a radical shift in public space making in Saudi Arabia. In terms of urban design, the list of the "first off" creations in Khobar goes long. Application of design standards, creation of infrastructure grids, introducing new building types, popularising new building forms and materials are just some of the many innovations. All of these precedents would cast their shadows on city planning in Saudi Arabia for generations to come. With the power of a booming oil industry, the rapid development

232 | The Journal of Public Space, 6(I), 202I| ISSN 2206-9658 City Space Architecture / UN-Habitat 
of Khobar was the product of several factors working in concert such as foreign investment, imported expertise, local demand and urbanization.

Its street grid was nothing short of a striking contrast to the local tradition. After the plan was launched in 1947, Khobar assumed the role of the local counterpart to the typical company town typology which developed in North and South America over the past two centuries. The contemporaneous regional company towns, such as Al-Ahmadi in Kuwait, maintained a lot of similarity with the typical company town form, which is characterized by composite footprint and agglomeration of different urban grid types in one place. Khobar, however, was different. The composite plan of a typical company town was deconstructed into separate public and private urban grids. Khobar public grid became a city that is open for all and free from the control of the founding company, which in the case of Aramco kept a separate and exclusive suburban-like campus at a safe distance in Dhahran.

Until Khobar became a thriving new city, the idea of a modern and cosmopolitan public space in Saudi Arabia was a feature that can only be found in established cities abroad. King Khalid street scored that high note until it became known locally as "the ChampsElysees of Saudi Arabia." Its current condition might not help to draw that conclusion but the passionate local narrative and the special place this street has in the public memory paint an image of a lively, liveable, equitable and accessible public space for all. The gradual decline of King Khalid street is a compound result of fundamental social, economic and urban changes, which disrupted and still continue to disrupt the city structure. By simply looking back at the past life of this street as opposed to its condition today, one can only see a greatly missed opportunity. There is no reasonable future outlook at this stage but to learn how to regenerate.

\section{Acknowledgement}

This work is dedicated to Dr Christian Winterhalter for his scholarly contribution on Khobar planning and architecture

\section{References}

Abrams, M. J. (1966). 'The Company Camp in Latin America: A Change in United States Mining and Petroleum Company Policy.' Land Economics, 42 (4), pp. 523-527.

Aga Khan Development Network (no date), Revitalisation Of Muharraq. Available at: https://www.akdn.org/architecture/project/revitalisation-muharraq (Accessed 27 July 2020).

Ajmi, N. (1995). Legacy of a lifetime: an essay on the transformation of Saudi Arabia. London: North Star Publishing.

Al-Dossary, M. (200I). A study of current residential buildings in Al-Khobar and the forces that shape them. PhD dissertation. University of Bath.

Al-Fawaz, N. (2018). Saudi graffiti artists transform old Khobar neighbourhood into giant canvases. Available at: https://english.alarabiya.net/en/life-style/art-and-culture/2018/03/06/Saudi-graffitiartists-transform-old-neighborhood-in-Khobar-into-giant-canvas.html (Accessed: 27 July 2020)

Al-Hathloul, S. and Anis-ur-Rahmaan, S. (1985). 'The evolution of urban and regional planning in Saudi Arabia.' Ekistics, 52 (3I2), pp. 206-2I 2.

Al-Hawwa, Y. (2019). Interviewed by Awadh Al-Fayyadh for MBC in a Week, 26 January. Available at: https://twitter.com/MBCinaWeek/status/I089I5570556585984I (Accessed: 26 July 2020).

Alissa, R. (20I3). The Oil Town of Ahmadi since 1946 From Colonial Town to Nostalgic City. Comparative Studies of South Asia, Africa and the Middle East, 33(I), pp. 4I-58. 
Al-Madani, A. (2017). 'Wasaț shāric al-taqāțuc al-awwal cām 1968 qabla taghyīr 'ittijāh al-saīr fîh', Alyaum, 24 March. Available at: https://bit.ly/2KYazmy (Accessed: 26 July 2020).

Al-Madani, A. (199I). Al-Khobar wa mā jāwarahā 'ayyām zamān. Dammam: Mațabic Al-Wafa'.

Al-Mubarak, F. (1999). "Oil, Urban Development and Planning in the Eastern Province of Saudi Arabia: The Case of the Arab American Oil Company in the 1930's-1970's", Journal of King Saud University: Architecture and Planning, II, PP. 3I-5I.

Al-Mulla, A. (199I). Tārīkh Hajr, (vol. I). Al-Ahsa: Mațabic Al-Jawād

Barth, H. K., and Quiel, F. (1986). 'Development and Changes in the Eastern Province of Saudi Arabia.' Geojournal, 13 (3), pp. 25।-259.

Buchli, V. (20I3). An anthropology of architecture. London: Bloomsbury.

Chalcraft, J. (20II). 'Migration and Popular Protest in the Arabian Peninsula and the Gulf in the 1950s and 1960s.' International Labor and Working-Class History, 79, pp. 28-47.

Correa, F. (2016). Beyond the city: Resource extraction urbanism in South America. Austin: University of Texas Press.

Crawford, M. (1995). Building the workingman's paradise: the design of American company towns. London; New York: Verso.

Croly, H. D. (20I4). The Promise of American life. Princeton: Princeton University Press.

Farmer, R. N. (1959). 'Local Entrepreneurship in Saudi Arabia.' The Business History Review, 33 (I), Pp. 73-86.

Farran, K. (2019). Personal conversation with the author, 30 May.

Fuccaro, N. (2013). 'Introduction: Histories of Oil and Urban Modernity in the Middle East.' Comparative Studies of South Asia, Africa and the Middle East, 33 (I), Pp. I-6.

Ham, D. (1944). I / /8 Opening a Bank at AL Khobar. British Library: India Office Records and Private Papers, IOR/R/I5/2/470, in Qatar Digital Library. Available at: https://www.qdl.qa/archive/81055/vdc_100000000241.0x0002a5 (Accessed: 27 July 2020).

Holston, J. (1989). The modernist city: an anthropological critique of Brasilia. Chicago: University of Chicago Press.

Khobar_history (2018). [Photograph of King Khalid street at night, circa 1980s]. [Twitter]. 3 March. Available at: https://twitter.com/khobar_history/status/969690124299722752 (Accessed 27 July 202I)

Jacobs, J. M. (1993). The Death and life of great American cities. New York: The Modern Library. Lesnikowski, W. (1982). Rationalism and Romanticism in Architecture. McGraw Hill Inc.

Mazzetto, S. (2018). Heritage Restoration as a Tool to Promote Architectural Identity in the Gulf Regions. Preservation, Digital Technology \& Culture, 47(I), Pp. 3-I I.

Parssinen, J. \& Talib, K. (1982). A Traditional Community and Modernization: Saudi Camp, Dhahran. JAE, 35(3), pp. I4- I7.

Salah, S. (n.d.). [View of King Khalid Street Entry Roundabout, circa 1960s ]. [image]. Available at: https://twitter.com/khalilfarran/status/I 032337931950804993 (Accessed 27 July 202I).

Salah, S. (1963). King Khalid Street Alkhobar 1963. [image] Available at: https://twitter.com/khalilfarran/status/I298685253II 299 I 745 (Accessed 27 July 202I).

Salah, S. (1968). King Khalid Street Alkhobar 1968. [image]. Available at: https://twitter.com/khalilfarran/status/I298685253II299I745 (Accessed 27 July 202I).

Shuaiby, A. M. (1976). The development of the Eastern Province, with particular reference to urban settlement and evolution in eastern Saudi Arabia. PhD dissertation. Durham University.

Southworth, M. and Ben-Joseph, E. (2003). Streets and the shaping of towns and cities. Washington, DC: Island Press.

Vitalis, R. (2007). America's kingdom : mythmaking on the Saudi oil frontier. Stanford, CA: Stanford University Press.

Winterhalter, C. (1989). 'Saudi Arabiens Bauwirtschaft im Wandel der Zeit.' Schweizer Ingenieur und Architekt, 107 (42), pp. II42-48. 